
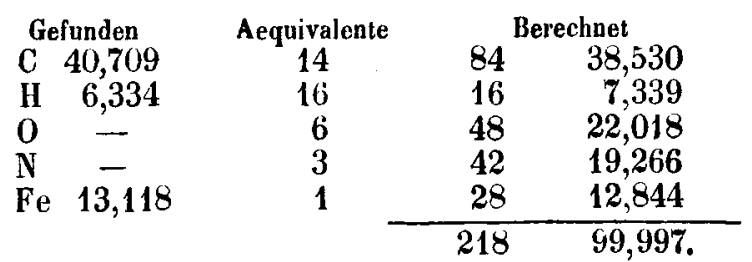

Diese Zahlen entsprechen dem Ferrocyanäthyl und 6 Aequivalenten Wasser Cfy $2 \mathrm{Ae}+6$ aq.

Auch diese Verbindung verliert ihr Wasser beim längern Slehen über Kalk, und bleibı das wasserfreie Ferrocyanäthyl Cfy 2 Ae zurück.

0,388 Grm. gaben 0,101 Eisenoxyd.

\begin{tabular}{|c|c|c|}
\hline \multirow{6}{*}{ 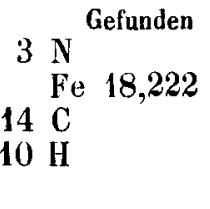 } & \multicolumn{2}{|c|}{ Berechnet } \\
\hline & 42 & 25,610 \\
\hline & 28 & 17,072 \\
\hline & 84 & 51,221 \\
\hline & 10 & 6,097 \\
\hline & 164 & 100,000 \\
\hline
\end{tabular}

Wie schon erwähnt, zersetzen sich die Verbindungen leicht, und rührt von dem immer mehr oder weniger sich gebildeten Eisencyanür der zu hohe Gehalt an Eisen her.

Methyl- und Amylalkohol scheinen sich so wie der Weingeist zu verhalten.

Wird Salzsäuregas in ein Gemisch von Ferrideyankalium und Alkohol geleitet, so findet unter selır starker Erwärmung eine Aufnahme desselben statt, und war das Gemisch bei dem Einleiten der Salzsäure gut abgekühlt, so scheidet sich beim vollständigen Erkalten der warm filtrirten Lösung eine grofse Menge eines kryslallinischen, chlorhaltigen, sehr leicht zersetzbaren Körpers ab. Die Untersuchung dieses Körpers ist noch nicht ausgeführt.

\title{
Ueber das sogenannte Fraxinin;
} von J. Stenhouse.

Es findet sich in vielen Lehrbüchern der Chemie L ïw ig's und Liebig's, auf die Angabe von Keller, Herberger 
und Buchner mitgetheilt, dafs die Rinde der gewöhnlichen Esche (Fraxinus excelsior) einen neutralen krystallisirbaren bitteren Stoff enthalte. Die Art der Darstellung dieses eigenthümlichen Stoffes, des Fraxinins, ist nach denselben wie folgt. Ein Auszug der Rinde wird, so lange noch ein Niederschlag fällt, zuerst mit neutralem, dann mit basischem essigsaurem Bleioxyd versetzt. Der Niederschlag wird abfiltrirt, die klare Flüssigkeit mit Schwefelwasserstoff behandelt und durch Filtration vom Blei befreit. Nach dem Eindicken und Slehenlassen während einiger Tage an einem kalten Orte scheiden sich dann die Krystalle von Fraxinin ab.

Ich behandelte 3 Pfund Eschenrinde ganz in der Art, wie angegeben.

Die aus der wässerigen Lösung erhaltenen unreinen Krystalle wurden zwischen Papier getrocknet und durch Umkrystallisiren aus Weingeist gereinigt. Nachdem sie farblos geworden waren, hatten sie ihren bitteren Geschmack verloren und einen süfsen angenommen. Sie hatten ganz den Character des Mannits und gaben bei der Verbrennung folgende Resultate :

0,273 Grm der Substanz im Wasserbade getrocknet gaben 0,194 Wasser und 0,389 Kohlensäure.

$\begin{array}{cccc} & \text { Mannit } & \text { berechnet } & \text { gefunden } \\ \text { C } & 12 & 39,5 & 38,897 \\ \text { H } & 14 & 7,7 & 7,882 \\ \text { O } & 12 & 52,8 & -\end{array}$

Der Fraxinin genannte Körper ist also nur Mannit, und Innfs der bittere Geschmack durch anhängende Unreinigkeiten verursacht seyn *).

*) Vgl. Bochleder und Schwarz, diese Annalen LXXXVII, 199.

D. $\mathbf{R}$. 